\title{
A INDISCIPLINA ESCOLAR: um estudo de caso no interior de Pernambuco
}

\section{SCHOOL INDISCIPLINE: A case study in Pernambuco}

\section{INDISCIPLINA ESCOLAR: Un estudio de caso en Pernambuco}

\section{Maria Aparecida Cabral Costa dos Santos ${ }^{1}$}

Helen Halinne Rodrigues de Lucena ${ }^{2}$

1. Graduada em Matemática. Especialista no Ensino da Matemática. Mestre em Ciência da Educação. Professora da Secretaria de Educação de Pernambuco. E-mail: cabralmaria22@yahoo.com.br

2. Pedagoga, Mestrado e Doutorado em Educação pela Universidade Federal da Paraíba (UFPB). Professora do Departamento de Educação da Universidade Federal da Paraíba, Campus III, em Bananeiras E-mail: helenufpb@gmail.com

RESUMO: Este estudo teve como objetivo analisar como a indisciplina no contexto escolar contribui na desconstrução do processo de ensino e aprendizagem dos educandos do $7^{\circ}$ ao $9^{\circ}$ ano da cidade de Vertente do Lério-PE. Tratou-se de uma pesquisa exploratória-descritiva com abordagem quali-quantitativa, com questionários aplicados a 15 estudantes e 11 professores, desenvolvida entre os meses de maio e junho de 2019. Constatou-se sobre o perfil dos professores pesquisados que a maioria é do gênero feminino, na faixa etária de 34 a 53 anos, casados e com filhos. Todos são licenciados na área que atuam e possuem pós-graduação, atuam a mais de 10 anos no ensino e não possuem outra atividade remunerada, com carga horária total de atividades de 30h/semanais. Sobre como lidam com a indisciplina, os professores afirmam que fazem uso de dinâmicas, diálogos, uso de jogos e atividades diversas na tentativa de amenizar a indisciplina escolar. Afirmam ainda que as situações de indisciplina que ocorrem em sala atrapalham o desempenho escolar e entendem que ela está vinculada a fatores internos, tais como: a infraestrutura, a administração, a relação professor-aluno, ao processo de ensino e aos fatores externos, como os problemas socioeconômicos, a baixa qualidade de vida e os conflitos de ordem familiar.

Palavras-chave: Ensino-Aprendizagem. Alunos. Professores. Escola.

\begin{abstract}
This study aimed to analyze how indiscipline in the school context contributes to the deconstruction of the teaching and learning process of students from the 7th to the 9th grade in the city of Vertente do Lério-PE. It was an exploratory-descriptive research with a qualitative and quantitative approach, with questionnaires applied to 15 students and 11 teachers, developed between the months of May and June 2019. It was found on the profile of the teachers surveyed that the majority are from the female, aged 34 to 53 years, married and with children. All are graduates in the area they work and have graduate degrees, have worked for more than 10 years in teaching and have no other paid activity, with a total workload of activities of $30 \mathrm{~h} /$ week. Regarding how they deal with indiscipline, teachers affirm that they make use of dynamics, dialogues, use of games and various activities in an attempt to alleviate school indiscipline. They also state that situations of indiscipline that occur in the classroom hinder school performance and understand that it is linked to internal factors, such as: infrastructure, administration, the teacherstudent relationship, the teaching process and external factors, such as socioeconomic problems, low quality of life and family conflicts.
\end{abstract}

Keywords: Teaching-Learning. Students Teachers. School.
RESUMEN: Este estudio tuvo como objetivo analizar cómo la indisciplina en el contexto escolar contribuye a la deconstrucción del proceso de enseñanza y aprendizaje de los estudiantes de $7^{\circ}$ a $9^{\circ}$ grado de la ciudad de Vertente do Lério-PE. Se trató de una investigación exploratoriodescriptiva con enfoque cualitativo y cuantitativo, con cuestionarios aplicados a 15 estudiantes y 11 docentes, desarrollados entre los meses de mayo y junio de 2019 . Se constató en el perfil de los docentes encuestados que la mayoría son del mujer, de 34 a 53 años, casada y con hijos. Todos son egresados en el área en que trabajan y tienen títulos de grado, han trabajado más de 10 años en la docencia y no tienen otra actividad remunerada, con una carga de trabajo total de actividades de 30h / semana. En cuanto a cómo afrontan la indisciplina, los docentes afirman que hacen uso de dinámicas, diálogos, uso de juegos y actividades diversas en un intento por paliar la indisciplina escolar. Asimismo, manifiestan que las situaciones de indisciplina que se dan en el aula dificultan el desempeño escolar y entienden que está vinculado a factores internos, como: infraestructura, administración, la relación docente-alumno, el proceso de enseñanza y factores externos, como problemas socioeconómicos, baja calidad de vida y conflictos familiares.

Palabras-clave Enseñanza-Aprendizaje. Estudiantes. Maestros. Colegio.

Recebido em: 14/05/2020

Aprovado em: 20/09/2020

Todo o conteúdo deste periódico está licenciado com uma licença Creative Commons (CC BY-NC-ND 4.0 Internacional), exceto onde está indicado o contrário. 


\section{Introdução}

Desde o surgimento das civilizações, o homem procurou maximizar seus conhecimentos em prol do desenvolvimento pessoal, humanístico, filosófico, tecnológico de forma justa e igualitária. O caminho para os seres humanos conseguirem resolver todas as questões que a civilização moderna dispõe é a educação, principalmente de qualidade. Os países que mais conseguiram se desenvolver foram aqueles os quais mais conseguiram avançar no conhecimento.

O caminho para se chegar ao ápice do desenvolvimento em qualquer área é conhecido por todos, mas a problemática para ter acesso à educação de qualidade é outra. A humanidade através de experiências se desenvolve a cada dia e a educação precisa fazer o mesmo em meio às novas culturas, e com a evolução tecnológica faz com que os educandos mudem seus interesses e perca o foco nas aprendizagens tradicionais as quais lhes são oferecidas. São notórias as reclamações feitas pelos os professores de que seus alunos não têm foco, não querem estudar, não prestam atenção, quando se estão atentos nas aulas não aprendem, sendo assim, a palavra mais citada entre os professores em relação às dificuldades de aprendizagem é a indisciplina (SAVIANI, 2018).

A indisciplina no cotidiano da escola é uma temática em destaque atualmente evidenciado nas principais publicações e livros, se apresentando como um dos principais elementos principais no dia a dia escolar, tornando-se um dos problemas centrais enfrentados pelos professores nas suas atividades laborais. Mesmo os professores evidenciando e reconhecendo os problemas de indisciplina na escola, priorizam os seus esforços na busca de estratégias para resistir aos seus avanços (SANTANA, 2012).

A preocupação profissional em conviver e resolver tais situações desencadeiam estresse relativo à disciplina na escola, faz com que o educador desperdice energias. Da mesma forma, proporcionam uma grande desmotivação para lecionar, uma vez que não conseguem desenvolver bem suas funções e o processo de ensinoaprendizagem fica comprometido proporcionando, no fim do ano letivo, um rendimento muito abaixo do planejado (SIQUEIRA, 2010).

A indisciplina escolar dificulta, dentre diversas outras coisas, o bom andamento de um trabalho pedagógico significativo. Dessa forma, acredita-se que é essencial identificar e compreender tais circunstâncias almejando de alguma forma facilitar a relação professor-aluno, buscando com que a aprendizagem se torne mais favorável e resolvendo os possíveis conflitos entre professores-alunos-escola (FERREIRA, 2019). O conhecimento psicológico e comportamental do ser humano possibilita e desencadeia uma melhoria no desempenho profissional e nas relações interpessoais de qualquer pessoa, com isso na educação não é diferente.

Conforme Velez (2010), o "fenômeno da indisciplina", infelizmente, proporciona um insucesso educativo, que gera um "insucesso escolar", no seu sentido mais restrito. Essa indisciplina no ambiente escolar parece estar vinculada, intrinsicamente, a fatores externos como os problemas socioeconômicos, inserção social, a qualidade 
de vida e os conflitos de ordem familiar e psicoemocionais, bem como, também, a fatores internos como a relação professor-aluno, a estrutura física escolar defasada e o atuação dos professores em lidar com tal situação. Diante disso, a indisciplina escolar pode chegar a gerar "a violência", extrapolando os muros das escolas. Dessa forma, objetivou-se analisar como a indisciplina no contexto escolar influencia no processo de ensino e aprendizagem dos educandos do $7^{\circ}$ ao $9^{\circ}$ ano da cidade de Vertente do Lério-PE.

\section{Metodologia da Pesquisa}

Para coletar as informações necessárias foi adaptado de Zanella (2009), um questionário composto de 31 questões abertas e fechadas. Portanto, destaca-se que o questionário é uma das técnicas disponíveis, mais importantes para a obtenção e registro dos dados. Sua versatilidade permite utilizá-lo como instrumento de investigação e de avaliação de pessoas, processos e programas de formação. É uma técnica de avaliação que pode incorporar aspectos quantitativos e qualitativos (GARCIA, 2003).

A elaboração da Matriz obedeceu às seguintes etapas: formulação dos objetivos, definição das variáveis a serem controladas de cada objetivo, definição dos indicadores pertinentes de cada variável (dimensão) e elaboração de uma matriz analítica para melhor estruturação do instrumento.

A matriz analítica foi baseada e adaptada dos estudos de Murcia et al. (2007) e Sant'ana (2012), abordando em especial: Fatores Educativos Centrados na Escola, Fatores Educativos Centrados no Professor, Fatores Educativos Centrados no Estudante, Fatores Educativos Centrados na Relação Professoraluno e Fatores Sociofamiliares. Algumas questões foram suprimidas e outras reformuladas resultando um instrumento com 28 questões.

A investigação utilizou como participantes quinze (15) alunos da escola objeto da pesquisa, sendo escolhidos aleatoriamente cinco (5) alunos, independente do gênero sexual, de cada uma das turmas $7^{\circ}, 8^{\circ}$ e $9^{\circ}$ anos das séries finais do Ensino Fundamental e onze (11) professores efetivos e contratados de uma escola em Vertente do Lério-PE. Essa escolha se justifica, pois, nas reuniões de Professores são justamente nessas turmas as maiores reclamações acerca da indisciplina em sala de aula.

Vale ressaltar que todos os alunos e professores citados neste estudo tiveram suas identidades preservadas devido aos princípios éticos da investigação, sendo atribuído os códigos P1, P2, ..., P10, P11 para os Professores participantes da pesquisa e os códigos A1, A2..., A14, A15 para os alunos participantes da pesquisa, dessa forma, garantindo o direito ao anonimato, e assim, poder serem identificadas todas as falas de todos os pesquisados nos resultados. Para a geração de dados foram aplicadas as normas éticas determinadas na Resolução nº 466/12 do Conselho Nacional de Saúde (CNS). 


\section{Resultados e Discussão}

Foi possível traçar o perfil social dos pesquisados e constatou-se que a maioria é do gênero feminino $(63,3 \%)$, prioritariamente com faixa etária acima de 40 anos (63,3\%), sendo 72,73\% casados e 81,82\% dos pesquisados tem filhos.

Esses dados corroboram com os estudos de Dos Santos e Rosso (2012), na cidade de Ponta Grossa$\mathrm{PR}$, que pesquisou a indisciplina em escolas públicas junto a 271 professores, cuja maioria era do gênero feminino $(80,8 \%)$ e com idade superior a 40 anos $(85,9 \%)$.

Sobre o perfil profissional dos pesquisados detectou-se que todos são licenciados, tendo cursado as graduações em instituição dos Estados de Pernambuco e da Paraíba. Apenas três não possuem pósgraduação e outros dois estão ministrando disciplinas que não são pertencentes a sua área de formação (Quadro 1).

Quadro 1: Perfil profissional dos professores pesquisados. 2019

\begin{tabular}{|c|c|c|c|c|}
\hline Pesquisados & Graduação & Instituição & Pós-Graduação & Leciona \\
\hline P1 & Ciências Biológicas & UNICAP & Especialização & Matemática \\
\hline $\mathbf{P 2}$ & Lic. Geografia & UPE-FFPNM & Especialização & Geografia \\
\hline P3 & Ciências Biológicas & Universidade Vale do Acaraú- UVA & $\begin{array}{c}\text { Especialização e } \\
\text { Mestrado }\end{array}$ & Biologia \\
\hline P4 & Letras & FAFICA & Especialização & $\begin{array}{l}\text { Língua Portuguesa } \\
\text { e Inglesa }\end{array}$ \\
\hline P5 & Letras & Universidade Vale do Acaraú-UVA & Não possui & Língua Portuguesa \\
\hline P6 & Pedagogia & UPE & Especialização & Artes \\
\hline P7 & Lic. ed. Física & UNOPAR & Não possui & Ed. Física \\
\hline P8 & Lic. Geografia & UPE-FFPNM & Especialização & $\begin{array}{l}\text { Geografia, História } \\
\text { e Ciências }\end{array}$ \\
\hline P9 & Lic. Geografia & $\begin{array}{l}\text { Fundação Francisco Mascarenhas- Patos- } \\
\text { PB }\end{array}$ & Especialização & $\begin{array}{l}\text { Geografia e } \\
\text { História }\end{array}$ \\
\hline P10 & Lic. Matemática & $\begin{array}{l}\text { Faculdade de Formação de Professor de } \\
\text { Nazaré da Mata }\end{array}$ & Não possui & Matemática \\
\hline P11 & Lic. História & Universidade Vale do Acaraú - UVA & Especialização & Geografia e Inglês \\
\hline
\end{tabular}

Fonte: dados da Pesquisa.

Apenas um professor está deslocado de sua área de formação. Todos os demais atuam em sua área especifica, e uma grande maioria possui pós-graduação. Este perfil não é preponderante para que os alunos possam ou não ser indisciplinados, porém, entendemos ser necessário que os professores estejam atuando em suas respectivas áreas de formação, para que fiquem estimulados e possam estimular e atrair a atenção dos alunos, visando uma melhor participação e uma consequente aprendizagem.

Esses dados também condizem com os estudos de Dos Santos e Rosso (2012), na cidade de Ponta Grossa-PR, que pesquisou a indisciplina em escolas públicas junto a 271 professores, cuja maioria tem pósgraduação e todos (100\%) são licenciados. 
Sobre o perfil profissional dos professores por atuação, identificou-se que a maioria $(72,72 \%)$ tem mais de 15 anos em atividade de docência e dedicam-se mais de 20 horas semanais a exercício do magistério (Quadro 2).

O perfil profissional dos professores pesquisados corrobora com os requisitos básicos de aulas que atraem a atenção dos alunos e podem proporcionar um melhor aprendizado, tendo em vista que possuem uma larga experiência na docência e tem cargas horárias suficientes para elaborar aulas mais dinâmicas.

Afirmamos isso nos baseando em Tardif (2014) quando diz que o saber profissional dos professores é constituído por diversos saberes, sendo um deles, os saberes experienciais, os que mais os auxiliam a lidar com as situações de trabalho que lhe são próprias, como a indisciplina, por exemplo.

Quadro 2: Perfil profissional dos professores pesquisados por atuação. 2019

\begin{tabular}{|c|c|c|c|c|}
\hline Pesquisados & $\begin{array}{c}\text { Tempo de } \\
\text { Atividade Docente }\end{array}$ & $\begin{array}{c}\text { Tempo de Carreira no } \\
\text { Magistério Público }\end{array}$ & $\begin{array}{c}\text { Carga Horária } \\
\text { Semanal }\end{array}$ & $\begin{array}{c}\text { Exerce outra atividade } \\
\text { remunerada }\end{array}$ \\
\hline P1 & 30 & 26 & 30 & NÃO \\
\hline P2 & 25 & 25 & 20 & NÃO \\
\hline P3 & 13 & 13 & 20 & NÃO \\
\hline P4 & 16 & 16 & 20 & NÃO \\
\hline P5 & 25 & 25 & 20 & N ̃̃O \\
\hline P6 & 16 & 16 & 20 & NÃO \\
\hline P7 & 01 & 01 & 20 & NÃO \\
\hline P8 & 25 & 25 & 20 & N ̃̃O \\
\hline P9 & 26 & 26 & 40 & NÃO \\
\hline P10 & 23 & 23 & 30 & \\
\hline P11 & 14 & 14 & 40 & \\
\hline
\end{tabular}

Fonte: dados da Pesquisa.

Esses resultados também foram encontrados nos estudos de Silva et al. (1999), na cidade de PelotasRS, cuja investigação demonstrou que o tempo de carreira era superior 15 anos.

Em relação ao perfil dos educadores pesquisados por formação continuada, verificou-se que a maioria $(90,91 \%)$ teve formação continuada ofertada pela secretaria municipal de educação no ano corrente (2019) e apenas 9,09\% não tiveram formação continuada no ano de atuação, porém alegam terem participado em anos anteriores em outro município.

Verificando quais os comportamentos que profissionais da educação consideram como indisciplina em suas aulas, 27,27\% afirmaram que é a "falta de interesse não tendo compromisso com as atividades propostas, falta de atenção ás aulas, falta de compromisso, desrespeito, agressões, vandalismo, entre outros", e $27,27 \%$ disseram que é a "falta de respeito com colegas, palavrões, agressão, falta de respeito com professores e outros profissionais da educação" (Quadro 3).

De acordo com os profissionais da instituição escolar pesquisada, as atitudes que eles evidenciam como "indisciplina" está correlacionada a falta concentração nas aulas, atos de vandalismo e a falta de respeito para com os profissionais, levando a entender que a indisciplina é de todos. Tais atos de frustram 
os objetivos que a educação propõe, que é educar, garantir autonomia, desenvolver; contribuir; estimular, promover e formar futuro cidadão.

Quadro 3: Conhecimento dos participantes da pesquisa sobre quais são os comportamentos que eles consideram como indisciplina em suas aulas. 2019

\begin{tabular}{|c|l|}
\hline Pesquisados & \multicolumn{1}{c}{ Falas dos Pesquisados } \\
\hline P1, P3, P10 & $\begin{array}{l}\text { Falta de interesse não tendo compromisso com as atividades propostas, falta de atenção as aulas., falta de } \\
\text { compromisso, desrespeito, agressões, vandalismo, entre outros. }\end{array}$ \\
\hline P2 & Não realizar as atividades, conversas paralelas, usos de palavrões e conversas inadequadas. \\
\hline P4 & Palavrões, quebrar ou danificar material escolar dentro da sala ou escola. \\
\hline P5, P7, P11 & $\begin{array}{l}\text { Falta de respeito com colegas, palavrões, agressão, falta de respeito com professores e outros profissionais da } \\
\text { educação. }\end{array}$ \\
\hline P6 & Não ficar na sala, não fazer atividade, responder mal o professor, colegas e funcionários. \\
\hline P8 & O uso de palavras de baixo calão e falta de respeito com colegas e professor. \\
\hline P9 & $\begin{array}{l}\text { Descumprimento das regras escolares em geral, não atender aos pedidos do professor na hora do aprendizado } \\
\text { e etc. }\end{array}$ \\
\hline
\end{tabular}

Fonte: dados da Pesquisa.

As inquietudes dos pesquisados refletem o mesmo discurso de Parrat-Dayan (2008), ao afirmar que a indisciplina em sala de aula é evidenciada pelo descumprimento das regras e normas e pela falta de limites como, por exemplo: falar durante as aulas o tempo todo, não levar material necessário, ficar em pé, interromper o professor, gritar, andar pela sala, jogar papeizinhos nos colegas e no professor, dentre outras atitudes que impedem os docentes de ministrarem as aulas com mais qualidade.

Mesma tendência é percebida no trabalho de Queiroga (2016), que realizou um trabalho intitulado, “Agressividade e Indisciplina Infantil: Reflexões sobre as causas e a intervenção no contexto escolar" numa Escola Estadual de Ensino Fundamental e Médio, o qual teve como "sujeito da pesquisa" 7 professores e 20 alunos, cujos resultados foram semelhantes.

Analisando quais as estratégias adotadas pelos docentes para intervir em casos de atos conflituosos ou indisciplinares, a maioria diz que tenta apelar para a "conversação e conhecê-los melhor em buscar de traçar novas estratégias, outros falam que trazem novas proposta de ensino como por exemplo, aulas mais dinâmicas" (Quadro 4).

É importante observar que nessa escola a comunidade utiliza várias estratégias para conter a indisciplina. Os professores, por exemplo, recorrerem ao diálogo, às atividades correlacionadas com dia a dia, aos jogos e à dinâmica; mostrado que os profissionais não desistiram de buscar atender os objetivos da educação.

Essas afirmativas corroboram com a pesquisa de Silva (2014), que estudaram sobre a gestão escolar e as consequências da indisciplina para o processo ensino-aprendizagem nas turmas da educação básica: a experiência de uma Escola em Macapá- AP, onde 75\% dos professores recorrem as conversas para solucionar problema de indisciplina. 
Quadro 4: Conhecimento dos participantes da pesquisa sobre quais as estratégias pedagógicas e metodológicas que você utiliza para a intervenção com estudantes que apresentam comportamentos indisciplinados nas suas aulas. 2019

\begin{tabular}{|c|l|}
\hline Pesquisados & \multicolumn{1}{c|}{ Falas dos Pesquisados } \\
\hline P1 & O diálogo \\
\hline P2 & Conversas e debater sobre temas pertinentes ao meio que vive, Uso de atividades de interesse do aluno. \\
\hline P3 & Atenção e conversa \\
\hline P4 & Jogos, dinâmica, música e seminários. \\
\hline P5 & $\begin{array}{l}\text { É preciso empenhar-se em conhecê-los bem, como seus interesses podem ser explorados e colaborar com } \\
\text { esse processo na diversificação de estratégias. }\end{array}$ \\
\hline P6 & Procuro dialogar com eles dentro da turma e fazer atividades mais interessantes. \\
\hline P7 & Tento conversar e mostrar com atitudes uma forma para que eles respeitem para ser respeitados \\
\hline P8 & Converso individual, pois é preciso saber a fonte desta agressividade para resolver. \\
\hline P9 & Clamo sua atenção pedindo-lhe que mude tal comportamento indisciplinar durante minhas aulas. \\
\hline P10 & $\begin{array}{l}\text { Atividades em grupo para tentar socializar ele com o trabalho que está sendo dado, converso sobre a } \\
\text { importância da escola com seu futuro. }\end{array}$ \\
\hline P11 & Tento trazer aulas diferentes para chamar atenção deles. \\
\hline
\end{tabular}

Fonte: dados da Pesquisa.

Para Benette e Costa (2008), torna-se necessário um maior envolvimento por parte da escola em busca de alternativas de intervenções para o enfrentamento de conflitos na sala de aula. Enfatiza-se que o trabalho coletivo é o principal instrumento de viabilização dessas ações. O diálogo, o estudo e a cooperação são os instrumentos que possibilitarão o caminho na busca por uma disciplina que considere o respeito como condição principal nas relações existentes na escola na busca por um melhor processo de ensinoaprendizagem.

Sobre os fatores que na percepção dos pesquisados explicam os diversos comportamentos referentes à indisciplina dos estudantes no contexto escolar a maioria responsabilizou a "família" (72,72\%), mas também além de responsabilizar os pais como principal fator que contribui para a indisciplina na escola, eles também agregam a "falta de perspectiva de futuro; interesse em estudar; problemas sociais e falta de poder econômicos" (Quadro 5).

Quadro 5: Conhecimento dos participantes da pesquisa sobre quais os fatores que na sua percepção explicam os diversos comportamentos referentes à indisciplina dos estudantes no contexto escolar. 2019

\begin{tabular}{|c|l|}
\hline $\begin{array}{c}\text { Pesquisados } \\
\text { P1 }\end{array}$ & \multicolumn{1}{c|}{ Falas dos Pesquisados } \\
\hline P2 & A falta de compromisso \\
\hline P3 & Problemas sociais e familiares. \\
\hline P4 & Desestrutura familiar, trauma de infância, criação e amizades. \\
\hline P5 & O descumprimento de regras, a desobediência familiar, a forma como os alunos lidam comas emoções etc. \\
\hline P6 & Falta de respeito, comprometimento, visão de futuro. \\
\hline P7 & $\begin{array}{l}\text { Falta de atenção dos pais em casa, isso leva os alunos acharem que tem todo direito, enquanto também tem } \\
\text { obrigações. }\end{array}$ \\
\hline P8 & A falta de comprometimento dos pais com os filhos, escola e atividades escolares. \\
\hline P9 & $\begin{array}{l}\text { Ambiente familiar em vive o aluno; grau de escolaridade baixa de pais ou responsáveis; fator econômico; } \\
\text { descuido dos pais com os filhos. }\end{array}$ \\
\hline P10 & $\begin{array}{l}\text { Falta de acompanhamento dos pais em casa; compromisso dos próprios estudantes nas atividades propostas; } \\
\text { valorização dos estudos como preparar o caminho para seu futuro; muitos não têm visão de futuro e estudam } \\
\text { por estudar, os pais impõem ir para escola. }\end{array}$ \\
\hline P11 & No meu ponto de vista é totalmente familiar \\
\hline
\end{tabular}

Fonte: dados da Pesquisa. 
Verificando os motivos que na visão dos professores levam os estudantes a agirem como "indisciplinados", evidenciou-se que as causas estão associadas à desestrutura familiar desde fator econômico, grau de instrução, interesses na formação dos filhos e valores éticos e morais, até a falta de perspectivas de futuro. Apesar dessas associações é importante ressaltar que a escola também é responsável pela formação de futuros cidadãos e como tal, com isso, é necessário que esta se torne também protagonista e crie condições, regras e formas para que os alunos possam cumprir dentro do espaço escolar, e, repliquem enquanto seres sociais.

Esse mesmo olhar foi encontrado no estudo de Salvador (2003), ao estudar o "Olhar a escola e os outros: Vivências de alunos de $9^{\circ}$ ano com atitudes de indisciplina". A pesquisadora avaliou os alunos do $9^{\circ}$ e detectou que $25,5 \%$ dos estudantes falam que "a educação é dada em casa" e $25 \%$ dizem que “intervenção dos pais às vezes é importante”.

Para Oliveira (2005), quando o professor souber ouvir o aluno sobre suas dificuldades, pessoal ou escolar, a melhoria no relacionamento e no clima de sala de aula irá melhorar significativamente. Porém, tal atitude, não se trata de atender as vontades dos alunos, mas sim de aproximar-se deles e conhecer suas dificuldades para melhor exercer seu papel de educador.

Acerca do conhecimento dos participantes da pesquisa sobre quais os prejuízos pedagógicos provocados pela indisciplina em suas aulas, 63,63 dizem que os alunos têm prejuízo na aprendizagem, $18,18 \%$ dos professores falam que "eles (alunos) ficam prejudicados, prejudica os alunos que querem estudar, atrapalha muito até a linha de pensamento de professor quando está explanando o conteúdo"; $18,18 \%$ afirmam que atrasa o andamento dos conteúdos; 9,09\% deixa claro que os alunos acabam influenciados os demais alunos na falta de comprometimento com os estudos e 9,09 \% afirmam que a frequência escolar (Quadro 6).

Quadro 6: Conhecimento dos participantes da pesquisa sobre quais os prejuízos pedagógicos provocados pela indisciplina em suas aulas. 2019

\begin{tabular}{|c|l|}
\hline Pesquisados & \multicolumn{1}{c|}{ Falas dos Pesquisados } \\
\hline P1 & Influencia na falta de compromisso dos demais alunos \\
\hline P2 & Atraso do conteúdo, reflexo nos outros alunos. \\
\hline P3 & Frequência e rendimento escolar. \\
\hline P4 & Notas baixas, reprovação. \\
\hline P5 & Falta de aprendizagem \\
\hline P6 & $\begin{array}{l}\text { Eles ficam prejudicados, prejudica os alunos que querem estudar, atrapalha muito até a linha de pensamento } \\
\text { de professor quando está explanando o conteúdo. }\end{array}$ \\
\hline P7 & Perdemos tempo para passar os conteúdos, resolvendo os problemas de indisciplina. \\
\hline P8 & Com isso o nível de aprendizagem cai. \\
\hline P9 & Notas baixas e baixo nível de aprendizado dos conteúdos ministrados. \\
\hline P10 & O aluno não faz as atividades; notas baixas nas avaliações e atividades somatórias. \\
\hline P11 & E a aprendizagem do aluno. \\
\hline
\end{tabular}

Fonte: dados da Pesquisa. 
As consequências que a "indisciplina" pode causar são diversas, e muito discutidas em todos os âmbitos educacionais, já que reflete no rendimento escolar individual e coletivo dos estudantes, principalmente para um país que vem buscando melhorias em seus níveis educacionais há curto prazo.

Conforme Banaletti e Dametto (2015), os atos indisciplinares também geram inúmeras consequências em todo o contexto escolar. Existem também, as consequências geradas junto aos professores que perdem muito tempo de sua aula tentando acomodar seus alunos, conseguindo a atenção desejada para explicar o conteúdo e realizar as atividades, implicado em sérios danos ao desenvolvimento de conteúdos e aprendizagens. Além do mais, quando um grupo de alunos não está colaborando, sem dúvida o restante da turma também acaba por sofrer com isso. Enquanto uns acatam a disciplina e outros resistem a ela, o professor fica em meio a esta situação e seu trabalho acaba não sendo eficaz.

De acordo com Sant'ana (2012, p. 42), a indisciplina escolar está vinculada a fatores internos, tais como: a infraestrutura, a administração, a relação professor-aluno e ao processo de ensino e aos fatores externos como os problemas socioeconômicos, a baixa qualidade de vida e os conflitos de ordem familiar.

No intuito de validar as respostas dos professores pesquisados foi aplicado a Matriz Analítica para confrontar os dados e identificar possíveis dissociações entre as respostas apresentadas pelos pesquisados. Os dados estão expressos a seguir.

Os professores investigados atribuem maior responsabilidade aos fatores sociofamiliares $(90,9 \%)$ pela ocorrência da indisciplina escolar (Tabela 1). Embora os percentuais de resposta sejam iguais nos fatores educativos centrados na escola e na relação professor-aluno, todos os demais discordaram haver fatores educativos centrados exclusivamente no estudante.

Vale ressaltar que as opiniões dos professores deixam claro que eles consideram a família como a principal propulsora de valores e éticos, morais e formadoras educacionais, e tais responsabilidades que autora era dada a família tem sido dado à escola. Por tudo isso, as causas de indisciplina estão sendo associadas aos fatores familiares, fato que precisa de uma ampla discussão, até porque a sociedade tem passado por diversas mudanças e com a educação não é diferente, o modelo de estudante do século XX não é igual ao do XXI.

Tabela 1: Opinião dos professores pesquisados considerando as dimensões dos fatores associados à indisciplina escolar. 2019

\begin{tabular}{lccc}
\multicolumn{1}{c}{ Dimensão } & Concordo & Indeciso & Discordo \\
$\mathbf{\%}$ & \% & 18,18 & 63,64 \\
\hline Fatores Educativos Centrados na Escola & 18,18 & 9,10 & 90,90 \\
\hline Fatores Educativos Centrados no Professor & - & - & 100 \\
Fatores Educativos Centrados no Estudante & - & 18,18 & 63,64 \\
Fatores Educativos Centrados na Relação Professor-aluno & 18,18 & - & 9,10 \\
\hline Fatores Sociofamiliares & 90,90 & & \\
\hline
\end{tabular}

Fonte: dados da Pesquisa. 
Esses resultados encontrados revelam que os professores consideram os fatores sociofamiliares como principal dimensão associada à indisciplina em suas aulas. Tal constatação também foi evidenciada em alguns outros estudos que destacaram que de quando os alunos enfrentam com problemas familiares apresentam também um nível de problemas de indisciplina na escola (SANT'ANA, 2012; PENNA, 2010; YAHAYA et al., 2009).

A análise pormenorizada considerando os indicadores de cada dimensão (Tabela 2) revelou que os fatores educativos centrados no estudante como compromisso escolar (90,9\%), características pessoais (78,78\%) foram apontadas pelos professores como os maiores responsáveis pela indisciplina dentro da escola e nas aulas. Tal resultado se contrapõe aos dados anteriores da Tabela 1, onde os mesmos pesquisados foram enfáticos em expressar que esses fatores não estavam associados à indisciplina escolar. Isto expressa uma possível falta de critérios e de conhecimentos sobre a indisciplina no contexto escolar onde atuam. Além de discordarem que a indisciplina esteja associada aos fatores sociofamiliares como Relações Pais e Filhos $(95,5 \%)$ e relações externas $(86,36 \%)$ e aos fatores educativos centrados no professor como a organização da Aula $(77,27 \%)$ e nível de satisfação profissional dos professores $(69,69 \%)$.

Considerando a opinião dos professores sobre os fatores associados à indisciplina, as opiniões divergem: uns associam que está centrado no estudante outros dizem que está associado à escola, referente à falta medidas educativas. De fato, entendemos que a responsabilidade de educar não pode ser apenas de um agente, como se deu na Tabela 1, pois os professores responsabilizaram apenas a família como propulsora de disciplina/indisciplina, e na verdade todos (família, escola e a sociedade) têm a função de cooperar na formação humana. Isso significa que a indisciplina não está apenas associada a questão familiar, mas, sendo algo muito mais amplo e difícil de ser solucionado.

Tabela 2: Opinião dos professores pesquisados considerando os indicadores dos fatores associados à indisciplina escolar. 2019

\begin{tabular}{lcccc}
\multicolumn{1}{c}{ Dimensão } & Indicadores & Concordo & Indeciso & Discordo \\
& & \% & \% & \% \\
\hline & Clima Escolar & 15,15 & 6.06 & 78,79 \\
Fatores Educativos & Medidas Preventivas & 54,54 & - & 45,45 \\
Centrados na Escola & Estrutura Física e Recursos Pedagógicos & 15,15 & 9,09 & 75,75 \\
& Conteúdo Pedagógico & 9,09 & 18,18 & 72,72 \\
Fatores Educativos & Organização da Aula & 22,72 & - & 77,27 \\
Centrados no Professor & Satisfação Profissional & 12,12 & 18,18 & 69,69 \\
Fatores Educativos & Compromisso Escolar & 90,90 & - & 9,09 \\
Centrados no Estudante & Características Pessoais & 78,78 & 3,03 & 18,18 \\
Fatores Educativos & Conflitos Escolares & 12,12 & 12,12 & 77,75 \\
Centrados na Relação & Gestão de Conflitos & 36,36 & 9,09 & 54,54 \\
Professor-aluno & Relações Externas & 13,63 & - & 86,36 \\
Fatores Sociofamiliares & Relações Pais e Filhos & 4,54 & - \\
\hline
\end{tabular}

Fonte: dados da Pesquisa. 
Sobre esses dados, os estudos de Estévez, Musitu e Herrero (2005) e Jerome, Hamre e Pianta (2009) confirmam que os estudantes com menor apego familiar exibem mais conflitos com os professores, indicando também, que a falta de diálogo ou a má comunicação entre pais e filhos estão associados ao comportamento violento na escola.

Para Sant'ana (2012), pode contribuir para a indisciplina na escola, além dos fatores familiares, os fatores econômicos, ao impacto da mídia e a outros fatores ambientais. Existindo também, as parcelas de culpas dos próprios professores através das suas faltas de experiências ou omissões em suas atividades laborais diárias.

De modo geral, os professores investigados também reconhecem o papel da escola no comportamento do estudante, visto que houve opiniões acerca dos fatores educativos centrados na escola. $\mathrm{O}$ corpo docente mostra-se mais sensível quanto à percepção das medidas preventivas (MITCHELL; BRADSHAW; LEAF, 2010). Porém, esses resultados contrariam o estudo de Yahaya et al. (2009) que ressaltou que a maioria dos professores associou o ambiente escolar como um dos fatores que influenciam nos problemas de indisciplina entre os estudantes, dentre eles, e conforme Santos et al. (2008), o elevado número de estudantes na turma e as características da estrutura escolar que conserva os estudantes por longos períodos imobilizados em carteiras.

Ao estratificar os dados de acordo o gênero dos participantes (Tabela 3), constatou-se algumas opiniões divergentes em determinadas dimensões, muito embora os pesquisados concordem que os fatores sociofamiliares sejam os principais fatores associados à indisciplina Escolar. Enquanto que os professores também atribuem responsabilidade aos fatores educativos centrados nos estudantes (36,36\%), as professoras consideram os fatores sociofamiliares $(63,64 \%)$ para a ocorrência de indisciplina.

Tabela 3: Opinião dos professores pesquisados considerando os indicadores dos fatores associados à indisciplina escolar por gênero dos colaboradores. 2019

\begin{tabular}{|c|c|c|c|c|c|}
\hline Dimensão & Indicadores & $\begin{array}{c}\text { Concordo } \\
\%\end{array}$ & $\begin{array}{c}\text { Indeciso } \\
\%\end{array}$ & $\begin{array}{c}\text { Discordo } \\
\%\end{array}$ & $\begin{array}{c}\text { Total } \\
\%\end{array}$ \\
\hline \multirow{3}{*}{$\begin{array}{l}\text { Fatores Educativos } \\
\text { Centrados na Escola }\end{array}$} & Masculino & 18,18 & 18,18 & - & 36,36 \\
\hline & Feminino & - & - & 63,64 & 63.64 \\
\hline & Total & 18,18 & 18,18 & 63,64 & 100 \\
\hline \multirow{3}{*}{$\begin{array}{l}\text { Fatores Educativos } \\
\text { Centrados no Professor }\end{array}$} & Masculino & - & 9,09 & 27,28 & 36,27 \\
\hline & Feminino & - & - & 63,63 & 63,63 \\
\hline & Total & - & 9,09 & 90,91 & 100 \\
\hline \multirow{3}{*}{$\begin{array}{l}\text { Fatores Educativos } \\
\text { Centrados no Estudante }\end{array}$} & Masculino & 36,36 & - & - & 36,36 \\
\hline & Feminino & 63,64 & - & - & 63,64 \\
\hline & Total & 100 & - & - & 100 \\
\hline Fatores Educativos & Masculino & 9,09 & 9,09 & 18,18 & 36.36 \\
\hline Centrados na Relação & Feminino & 9,09 & 9,09 & 45,46 & 63,64 \\
\hline Professor-aluno & Total & 18,18 & 18,18 & 63,64 & 100 \\
\hline \multirow{3}{*}{ Fatores Sociofamiliares } & Masculino & 27,27 & - & 9,09 & 36,36 \\
\hline & Feminino & 63,64 & - & - & 63,64 \\
\hline & Total & 90,91 & - & 9,09 & 100 \\
\hline
\end{tabular}

Fonte: dados da Pesquisa. 
Analisando a opinião das educadoras, é importante salientar o modo como era a educação há décadas, onde as famílias que tinham maior poder aquisitivo tinham acesso à educação, e as mulheres carregavam sob suas responsabilidades a educação dos filhos. Essas visões ainda percorrem até os dias de hoje, e assim, qualquer ato antiético, indisciplina ou que fere os princípios morais, a sociedade acaba sendo atribuído à família que não soube educar.

Normalmente as professoras conseguem envolver mais os estudantes nas aulas, dessa forma criando um clima motivacional mais favorável e desenvolvendo mais autoconfiança. Em contrapartida, os professores, na maioria das vezes, são mais rigorosos em relação à disciplina, mas ao mesmo tempo, mais compreensivos com a natureza e a atitude dos estudantes desordeiros (MURCIA, 2005; YAHAYA et al., 2009; SANT’ANA, 2012).

Apesar da a maioria dos pesquisados concordarem que os estudantes não mostram compromisso e interesse pelas aulas, também discorda que as características pessoais do estudante sejam fatores de indisciplina.

Estes dados são contrários à literatura levantada e analisada, uma vez que a indisciplina está associada a um desempenho escolar (MITCHELL, BRADSHAW; LEAF, 2010; SANT'ANA, 2012) e a um maior aumento de conflito nos primeiros anos de escolarização (JEROME; HAMRE; PIANTA, 2009). Outras características que foram observadas ressaltam que as meninas com maior aproximação com seus professores apresentam menor conflito e os adolescentes mais velhos referem menor envolvimento na escola (ZIMMER-GEMBECK; LOCKE, 2007).

\section{Sobre os alunos pesquisados}

Foi possível traçar o perfil dos pesquisados e verificou-se que $20 \%$ dos alunos que atualmente estudam no $7^{\circ}$ ano, foram reprovados nos $6^{\circ}$ anos, duas vezes. Também foi possível identificar que $20 \%$ dos estudantes do $8^{\circ}$ ano já foram reprovados no $7^{\circ}$ ano $(10 \%)$ e $8^{\circ}$ ano (10\%), ambos duas vezes. (Quadro 9). No entanto, $40 \%$ os estudantes pesquisados do $9^{\circ}$ ano responderam que foram reprovados uma única vez, $20 \%$ disseram que foram reprovados quando estudavam do $1^{\circ}$ ao $5^{\circ}$ ano do Ensino Fundamental e $20 \%$ falaram que foram reprovados quando estudavam no $7^{\circ}$ ano do Ensino Fundamental.

Ao analisar os dados relacionados à opinião dos alunos considerando a faixa etária e ano que foram reprovados, verificou-se que 33,33\% dos estudantes foram reprovados no Ensino Fundamental I e II, sendo que os índices se elevam no Ensino Fundamenta II ( $6^{\circ}$ ao $9^{\circ}$ ano) que corresponde a 26,66\%, indicando que se reprova mais no fundamental II. Além disso, ambos tinham 12 anos quando foram retidos.

Ao analisar a faixa etária que os estudantes desta escola foram reprovados, é notório que todos foram retidos com 12 (doze) anos e 2 (duas) vezes ao longo da vida estudantil. Com isso, se torna evidente que a transição de criança para adolescente pesa no compromisso escolar, necessitando de um acompanhamento 
familiar e educacional maior, visto que, existem vários atrativos para essa faixa etária, desviando assim o adolescente do foco nos estudos.

Esses dados estão de acordo com o conjunto de informações fornecidas no trabalho de Fernandes (2018), que elaborou um estudo nas escolas públicas do Estado do Rio de Janeiro. Ele trabalhou com uma mostra de 311 alunos do $8^{\circ}$ e $9^{\circ}$ anos, de ambos os gêneros. A pesquisa mostrou que o índice de aprovação escolar foi 64,3\% (200 alunos), enquanto 35,7\% (111 alunos) indicaram terem sido "reprovados de ano" pelo menos uma vez. Esta pesquisa apresentou avaliação semelhante no IDEB, correspondente ao ano de 2013 do Estado do Rio de Janeiro.

Segundo dados do Instituto Nacional de Estudos e Pesquisas Educacionais Anísio Teixeira (INEP), os índices de reprovação do Brasil caem consideravelmente quando comparado entre 2012 a 2018, nos anos iniciais do Ensino Fundamental em 2012 era 6,2\% em 2018 e caiu para 5,1\%; já o os anos finais do Ensino Fundamental era $11,7 \%$ e desceu para 9,5.

De acordo com os dados examinados foi possível identificar que os principais motivos que levam os alunos a serem reprovados na Escola pesquisada, são eles: (40\%) dos alunos não estudaram o suficiente, (40\%) tiveram dificuldades em organizar seus estudos e $20 \%$ dos discentes pesquisados afirmarem que seus educadores os perseguiram que não conseguiram entender a matéria e não foram capazes de captar as explicações dos educadores decorrente do "barulho" em sala (Quadro 7).

Quadro 7: Opinião dos alunos pesquisados considerando os motivos que contribuíram para reprovação. 2019

\begin{tabular}{|c|c|c|c|}
\hline \multirow{2}{*}{ FUI REPROVADO } & $7^{\circ}$ Ano & $8^{\circ}$ Ano & $9^{\circ}$ Ano \\
\hline & Motivos & Motivos & Motivos \\
\hline Meus professores me perseguiram & - & - & $\mathrm{X}$ \\
\hline A escola foi exige demais & - & - & $\mathrm{X}$ \\
\hline Meus professores não sabem explicar bem os conteúdos & - & $\mathrm{X}$ & $\mathrm{X}$ \\
\hline Não estudei o suficiente & $\mathrm{X}$ & $\mathrm{X}$ & $\mathrm{X}$ \\
\hline Tive dificuldade de organizar meus estudos & $\mathrm{X}$ & $\mathrm{X}$ & $\mathrm{X}$ \\
\hline Não consegui entender a matéria & $\mathrm{X}$ & $\mathrm{X}$ & $\mathrm{X}$ \\
\hline Não conseguia escutar as explicações com tanto barulho na sala & $\mathrm{X}$ & - & $X$ \\
\hline
\end{tabular}

Fonte: dados da Pesquisa.

É importante ressaltar que os próprios alunos associaram como principais motivos de suas reprovações o "estudar pouco"; fato este de grande relevância na reprovação, visto que quanto mais se estuda, mais se aprende. Também associaram sua retenção de série/ano à dificuldade que eles têm de “organizar seus estudos”, vale destacar a nossa compreensão de que o principal comprometimento de um estudante deve ser nos estudos, visto que eles então em formação, e é necessária dedicação para bom o êxito educacional. No conjunto de motivos, também culparam a dificuldade de "entender a matéria", sendo 
isso concebível do ponto de vista pedagógico, visto que a compreensão do conteúdo e a percepção dos estudantes sobre a capacidade que têm de utilizar convenientemente o que é aprendido (ZABALA, 1998), principalmente quando estes conteúdos têm relação e importância em suas vidas, impulsionaria mais o gosto pelo conhecimento, e, como consequência, diminuiria a indisciplina e a desistência ou reprovação na escola.

No estudo de Negreiros, Da Silva e Lima (2017), esses argumentos se confirmam quando, nas análises de uma pesquisa realizada, foram apontados pelos alunos as principais causas que influenciaram suas reprovações.. As respostas foram as mais variadas possíveis: 84\% atribuíram as causas da reprovação à falta de interesse, às conversas paralelas, à ausência de ajuda do professor, à má explicação e à falta às aulas; $8 \%$ atribuíram as causas da reprovação a viagens que fizeram; 4\%, por conta de familiares que estavam internados em hospital; e 4\% não opinaram.

De acordo com as respostas dos pesquisados na pesquisa de Sampaio (2004, p. 89) "[...] o fracasso não se explica apenas pela reprovação, e nem pela perda de um ou mais anos, repetindo séries; outra perda relevante acontece pelo distanciamento cada vez maior estabelecido entre os alunos e o conhecimento que a escola pretende transmitir".

Ao examinar dados referentes ao que os alunos pretendem fazer quando terminarem o Ensino Fundamental, a investigação apontou que $40 \%$ dos estudantes do $7^{\circ}$ ano pretendem continuar estudando, $20 \%$ querem trabalhar, $20 \%$ querem trabalhar e também continuar estudando, 20\% não sabem; já os dados dos alunos do $8^{\circ}$ ano revelaram que $60 \%$ dos estudantes pretendem somente continuar estudando, $20 \%$ trabalhar e $20 \%$ não sabem responder. Na sequência, os estudos com alunos do $9^{\circ}$ ano apontaram que $40 \%$ dos discentes pretendem continuar estudando, 20\% somente trabalhar e 40\% estudar e trabalhar (Quadro 8).

É considerável evidenciar que o sucesso do aluno depender muito do foco, e quando não se tem foco ou a escola não faz parte dos objetivos que os estudantes pretendem alcançar, ou os estudos passam a ser mera obrigação. O que leva ao descompromisso com esta área da vida.

Quadro 8: Opinião dos alunos pesquisados sobre o que pretendem fazer quando terminarem o ensino fundamental. 2019

\begin{tabular}{|c|c|c|c|}
\hline $\begin{array}{c}\text { O QUE VOCÊ PRETENDE FAZER QUANDO } \\
\text { TERMINAR O ENSINO FUNDAMENTAL }\end{array}$ & $\begin{array}{l}7^{\circ} \text { Ano } \\
\%\end{array}$ & $\begin{array}{l}8^{\circ} \text { Ano } \\
\%\end{array}$ & $\begin{array}{l}9^{\circ} \text { Ano } \\
\%\end{array}$ \\
\hline Somente continuar estudando & 40 & 60 & 40 \\
\hline Somente trabalhar & 20 & 20 & 20 \\
\hline Continuar estudando e trabalhar & 20 & - & 40 \\
\hline Ainda não sei & 20 & 20 & - \\
\hline Total & 100 & 100 & 100 \\
\hline
\end{tabular}

Fonte: dados da Pesquisa.

Tais aspirações corroboram com o estudo de Costa e Koslinski (2006), em seu trabalho intitulado "Entre o mérito e a sorte: escola, presente e futuro na visão de estudantes do ensino fundamental do Rio de 
Janeiro", entre escolas públicas e privadas, cujos resultados expressaram que os alunos, em sua maioria, de ambas as redes escolares, afirmam desejar completar o ensino médio, e alguns expressam dúvidas quanto à possibilidade de alcançar esse nível de ensino.

Analisando os dados referentes em que tipo de escola que os alunos pretendem estudar no ano subsequente, $60 \%$ os estudantes do $7^{\circ}$ ano pretendem estudar em qualquer escola, $40 \%$ afirmam que querem estudar em escola estadual; já, $80 \%$ dos discentes do $8^{\circ}$ ano relataram que não sabem em qual escola estudar e $20 \%$ disseram que almejam estudar em escolas estaduais; da mesma forma que $80 \%$ dos alunos $9^{\circ}$ ano, dizem que vão estudar em escola pública e $20 \%$ não sabem.

\section{Sobre a sala de aula}

Tendo em vista a investigação sobre a frequência com que as situações de indisciplina ocorrem em sala, a maioria afirmou que os professores têm que esperar muito pelo silêncio dos estudantes; que há barulho e desordem na sala de aula; que não conseguem estudar direito; que os alunos entram e saem da sala sem pedir licença; porém, que respeitam as regras de convivência da escola e que procuram os professores quando precisam de ajuda.

De acordo com os dados apresentados, é importante ressaltar que o barulho atrapalha as aulas de qualquer educador, e este perde tempo organizando a desordem, e isso de fato, prejudica o andamento das aulas e a explicação dos conteúdos, com isso dificultando que outros alunos aprendam com maior eficácia. Também é notório ressaltar que os estudantes desta escola falam que respeitam as regras das escolas, porém são indisciplinados, entram e saem da sala de aula sem pedir permissão, fazem barulho, conversam paralelamente durante a explanação do professor. Portanto, a conclusão é que as regras escolares neste ambiente não são claras ou falta reformular novas regras de convivência de forma ampla e democrática.

É de grande relevância destacar que os educandos assumiram seus atos ao falarem que entram e saem da sala de aula sem a devida permissão de seus professores, existe uma desordem em sala de aula e mesmo assim eles ainda dizem que respeitam as regras e ordens de convivência, mostrando que os discentes não sabem distinguir o que são regras de convivência ou estas não são claras nesta instituição escolar.

Sobre a opinião dos pesquisados em relação ao comportamento dos alunos durante a explanação dos conteúdos, detectou-se que a maioria acompanha a matéria exposta pelo professor, copia no caderno a matéria apresentada e realiza as atividades que o professor propõe, muito embora, também, conversam com os demais colegas durante a explanação dos conteúdos. Percebe-se aqui que alguns alunos, principalmente do $8^{\circ}$ e $9^{\circ}$ não ficam mais tão à vontade para esclarecer dúvidas surgidas no decorrer das aulas, esse fato se deve ao medo de se sentirem menos incapaz em relação aos outros estudantes no que diz respeito ao entendimento os conteúdos nas primeiras explicações. Uma quantidade significativa desses estudantes diz 
que nem sempre realizam as atividades, fato este considerado de dificuldade para o êxito da aprendizagem. Se alguns alunos não estão comprometidos com as atividades de classe ou de casa, a probabilidade é que desenvolvam posturas que atrapalham o desenvolvimento da aula, como as conversas paralelas que revelam pouco interesses nos estudos e que acabam por inviabilizar a aprendizagem e provocar a reprovação.

Ao analisar as respostas dos alunos pesquisados relacionando à postura que o profissional da educação adota nas aulas, as respostas foram:

- $100 \%$ incentivam os alunos das três turmas $\left(7^{\circ}, 8^{\circ}\right.$ e $9^{\circ}$ ano) a melhorarem tanto as notas como comportamento;

- 100\% estão dispostos a esclarecer dúvida ocorrida após a explanação dos conteúdos trabalhados;

- $100 \%$ dos professores dos $7^{\circ}, 8^{\circ}$ e $9^{\circ}$ deixam os alunos expor suas ideias;

- 100\% dos docentes explicam os conteúdos até o aluno aprender;

- $100 \%$ demostram interesses pelo o aprendizado dos educandos;

- 100\% organizam a apresentação dos conteúdos antes de expor; contudo, em relação à cobrança de aprendizado nas avaliações, $20 \%$ afirmam que os profissionais são injustos da forma de avaliar, e $80 \%$ acham justas a modo de avaliação dos educadores.

É considerável destacar, a partir destes dados, que os professores, na percepção dos alunos, estão comprometidos em contribuir com suas aprendizagens. Muitos estudantes reconhecem que seus docentes têm domínio dos conteúdos trabalhados, organizam e planejam bem as suas aulas, estão dispostos a esclarecer dúvidas, dão oportunidade para a discussão do tema abordado e realizam avalição de forma justa. Essas atitudes demostram que apesar das dificuldades de se manterem motivados pelos estudos, os estudantes percebem o compromisso educativo de seus professores. E este bom preparo dos professores no que se refere ao desempenho do seu saber profissional é uma realidade do nosso século. $\mathrm{O}$ estudo de Negreiros, Da Silva e Lima (2017) corrobora com estes dados, uma vez que $52 \%$ dos estudantes responderam que, os professores são bons, e a escola tem tudo de que os alunos precisam; 28\% disseram que não, as escolas deixam a desejar em termos de estrutura; $12 \%$ responderam mais ou menos; $8 \%$ não opinaram.

No discurso pedagógico, há, por outro lado, uma preocupação, com as diferentes estratégias de ensino viabilizadoras da aprendizagem, já que elas influenciam na motivação dos estudantes pelo estudo. A esse respeito, Nunes e Silveira (2009) enfatizam que não se aprende da mesma forma, por isso os estudantes precisam de diversas estratégias diferentes de aprendizagem para permiti-lhes um envolvimento mais ativo com o objeto do conhecimento. Além de diversificar as estratégias de ensino e aprendizagem, Tomáz (1996) entende que os conteúdos devem ser trabalhados a partir do conhecimento de mundo que os alunos apresentam. Desse modo, pouco adianta o professor trabalhar, por exemplo, a disciplina de 
matemática, de sua forma e do seu jeito (recorrendo apenas aos saberes curriculares), se não fizer sentido para o aluno esse conhecimento.

De acordo com os dados investigados nas turmas pesquisadas, considerando as relações interpessoais na escola, os dados revelaram que as relações entre colegas professores, direção, coordenação pedagógica e demais funcionários é razoável ou boa, com percentuais oscilando entre 60 e $100 \%$.

A esse respeito, Bee (1997), afirma que é nessa fase que as relações se tornam mais significativas pelo fato de que é a partir dessas amizades que os adolescentes transitam para a fase adulta. Suas interações sociais e entre seus pares e os que convivem no dia a dia são determinantes para como se relacionarão na sociedade na sua vida adulta.

Compreende-se, dessa maneira, que a indisciplina tem relação com a comunidade escolar. Sobre isso, embora as respostas da maioria dos estudantes tenham revelado a existência de uma boa convivência com a comunidade escolar, muitos registraram conflitos com diretor, professor, funcionários e coordenador, o que leva a suspeitar que esta vulnerabilidade das relações pode estar influenciando os comportamentos de indisciplina.

Assim, entende-se que é improvável que uma escola desenvolva a capacidade de pensar as relações sociais através da cooperação (sugerindo, por exemplo, aos alunos, que sejam mais solidários, cooperativos), se ela mesma, em suas práticas, não vivencia com seus estudantes, uma convivência em que as relações de reciprocidade se constituam em uma realidade.

Imaginemos uma criança ou adolescente que conviva em um ambiente no qual os valores como respeito, justiça e paz sejam trocados reciprocamente; e outra que lida com a violência, dominação e desrespeito. É mais provável, que nesta última, este estudante não se desenvolva moralmente, pois está sujeito da soberania dos que proclamam tais valores - a violência, dominação e desrespeito atuam, motivado por eles. Agora se esse adolescente vive em um local repleto de violência e miséria moral, em um ambiente onde a compaixão é vista como fraqueza, sua tendência natural a simpatia pode ser insensível dando lugar ao preconceito que a torna o ser indiferente aos estados afetivos alheios (LA TAILLE, 2007).

\section{Sobre a família}

Sobre o grau de instrução educacional das mães ou madrastas dos estudantes pesquisados, detectouse que a maioria possui até as séries finais do Ensino Fundamental, seguido do Ensino Médio Completo e das séries iniciais do Ensino Fundamental (Quadro 9).

A sociedade sempre relaciona os bons costumes e boa educação ao nível de instrução da família e ao poder aquisitivo que elas têm, mas a sociedade moderna das últimas décadas vem passando por transição e mudando os seus conceitos, porém ainda é notório que tanto mais as famílias têm grau elevado de 
instrução, maior e mais poder aquisitivo, mais oportunidade elas têm de oferecer uma educação de qualidade para seus filhos, este fato se dá, porque elas entendem melhor o funcionamento escolar, sabem que para os filhos acender, precisa primeiro de educação; buscam as melhores instituições escolares, com o objetivo de elitizar seus descendentes e investir mais valores financeiros e tem em sua maioria maior comprometimento com a educação de seus filhos.

Quadro 9: Informações dos estudantes pesquisados sobre nível de instrução de sua mãe ou madrasta. 2019

\begin{tabular}{|l|c|c|c|}
\hline \multicolumn{1}{|c|}{ ATÉ QUE SÉRIE SUA MÃE/MADRASTA ESTUDOU? } & $\mathbf{7}^{\mathbf{0}}$ Ano (\%) & $\mathbf{8}^{\mathbf{0}}$ Ano (\%) & $\mathbf{9}^{\mathbf{o}}$ Ano (\%) \\
\hline Nunca estudou & 20 & - & - \\
\hline Séries Iniciais do Ensino Fundamental & - & 20 & 20 \\
\hline Séries Finais do Ensino Fundamental & - & 40 & 40 \\
\hline Ensino Médio Incompleto & 20 & - & - \\
\hline Ensino Médio Completo & 20 & 20 & 20 \\
\hline Ensino Superior Incompleto & - & 20 & - \\
\hline Ensino Superior Completo & 20 & - & - \\
\hline Não sei. & 20 & - & 20 \\
\hline
\end{tabular}

Fonte: dados da Pesquisa.

Essas informações correspondem a pesquisa de Siqueira (2017), em sua pesquisa realizada em duas escolas de Ensino Fundamental I e II da rede municipal no Município de Tacaratu-PE, com 1.200 educandos e 50 professores, onde os dados revelaram que $61,2 \%$ das mães estudaram apenas o primeiro grau incompleto, $18,8 \%$ tem primeiro grau completo, $1,1 \%$ tem graduação e $1,8 \%$ são especialistas.

No que diz respeito ao nível de instrução dos pais ou padrastos dos pesquisados a maioria não sabe se o pai estudou, seguido dos que estudaram até as séries iniciais do Ensino Fundamental. Vale salientar dois pais dos alunos da turma do $7^{\circ}$ ano concluíram um Curso Superior (Quadro 10).

Quadro 10: Informações dos estudantes pesquisados sobre nível de instrução de seu pai ou padrasto. 2019

\begin{tabular}{|l|c|c|c|}
\hline \multicolumn{1}{|c|}{ ATÉ QUE SÉRIE SEU PAI/PADRASTO ESTUDOU? } & $\mathbf{7}^{\mathbf{0}}$ Ano (\%) & $\mathbf{8}^{\mathbf{o}}$ Ano (\%) & $\mathbf{9}^{\mathbf{0}}$ Ano (\%) \\
\hline Nunca estudou & 20 & 20 & - \\
\hline Séries Iniciais do Ensino Fundamental & - & 40 & 20 \\
\hline Séries Finais do Ensino Fundamental & 20 & - & 20 \\
\hline Ensino Médio Completo & - & 20 & - \\
\hline Ensino Superior & 40 & - & - \\
\hline Não sei. & 20 & 20 & 60 \\
\hline
\end{tabular}

Fonte: dados da Pesquisa.

O quadro 18 apresenta que os pais dos alunos do $7^{\circ}$ ano tiveram mais oportunidade de elevar seus estudos e chegar mais ao nível superior, porém mesmo diante desse fato os alunos de todas as séries revelaram comportamento de desobediência.

Tais dados segue a mesma tendência do estudo de Martins et al (2016), que ao retratarem acerca dos agentes geradores da indisciplina escolar na percepção dos docentes e discentes do Ensino Fundamental em uma escola estadual situada na periferia do município de Manaus, Amazonas, onde detectou-se que a 
maioria dos pais/padrastos possui Ensino Fundamental incompleto (29\% e 31\%), Ensino Fundamental completo (28\% e 19\%) e Ensino Médio completo (22\% e 26\%).

Segundo Oliveira (2005), o baixo nível de escolaridade da família pode ser um agravante, visto que a problemática da indisciplina está entrelaçada a vários fatores, sendo um deles, a família. Isso implica dizer que a indisciplina não está associada apenas a fatores escolares, mas também é um reflexo do ambiente familiar em que o estudante convive, sobretudo, quando se entende que os agentes formadores de valores e condutas dos estudantes são também as pessoas do convívio mais próximo, os quais direcionam e influenciam, direta ou indiretamente, seus comportamentos.

\section{Sobre o aluno}

De acordo com as informações acerca da importância que estudo tem na vida dos estudantes e principalmente para o futuro profissional de cada um, $40 \%$ dos alunos do $7^{\circ}$ ano consideram importante, $20 \%$ afirmaram ser decisiva e $40 \%$ declararam que não sabem; entretanto, $100 \%$ os educandos do $8^{\circ}$ ano consideram importante; enquanto $40 \%$ os aprendizes do $9^{\mathrm{a}}$ ano consideram que o estudo é importante, e $60 \%$ pensam ser decisivo.

Ao pensar em educação, precisamos saber qual a importância dela em nossas vidas, estudar por obrigação torna-se a aprendizagem obsoleta e chata. Partindo do pressuposto de que os estudantes podem estar estudando sem motivação e por isso são desmotivados, o Quadro 19 abordou a importância dos estudos para o futuro profissional de cada um estudante, e as respostas dos anos finais do Ensino Fundamental II foram mais satisfatórias no que se refere que se espera de um aluno. Eles consideram a educação importante em suas vidas, e isso é um fator importante no comprometimento com a vida escolar, apesar das circunstancias sociais em que estejam inseridos.

Essas relações estabelecidas pelos pesquisados com a escola são, portanto, muito relativas às experiências pelas quais eles passam. Os interesses por estudar, as motivações que os levam a se mobilizarem, dependem basicamente dessas experiências. Para Charlot (2009), a importância do estudar e do aprender requer uma atividade intelectual. Só se engaja numa atividade quem lhe confere um sentido. Quando esse sentido é afastado do resultado visado pela ação de estudar, o engajamento nesta é frágil.

\section{Considerações Finais}

Quanto ao perfil dos alunos pesquisados, observou-se que a maioria está dentro da faixa etária; nunca foi reprovado e uma pequena parte repetiu de ano uma única vez, sendo que, desses, poucos estavam cursando do $1^{\circ}$ ao $5^{\circ}$ ano do Ensino Fundamental e outros quando estudavam $7^{\circ}$ ano do Ensino Fundamental. Com isso, se torna evidente que a transição de criança para adolescente pesa no compromisso escolar, 
necessitando de um acompanhamento familiar e educacional maior, visto que, existem vários atrativos para essa faixa etária, desviando assim as crianças e os adolescentes do foco nos estudos.

Verificou-se que a média de alunos por sala é de 35 alunos e existe indisciplina. Portanto, nesta escola a quantidade de alunos por sala não é o fator preponderante da disciplina ou indisciplina na escola.

Sobre os professores pesquisados constatou-se que a maioria é do gênero feminino, prioritariamente com faixa etária acima de 40 anos, sendo a maioria casados e pais de pelo menos um único filho. Todos são licenciados, tendo cursado as graduações em instituição dos Estados de Pernambuco e da Paraíba. Apenas três não possuem pós-graduação e outros dois estão ministrando disciplinas que não são pertencentes a sua área de formação. A maioria tem mais de 15 anos em atividade de docência e dedicamse mais de 20 horas semanais a exercício do magistério. A maioria teve formação continuada, ofertada pela secretaria municipal de educação no ano corrente (2019) e apenas uma pequena parte dos professores não tiveram formação continuada no ano de atuação, porém alega ter participado em anos anteriores em outro município.

Sobre os fatores que geram a "indisciplina", na percepção dos pesquisados, estão "família", mas também, a "falta de perspectiva de futuro; interesse em estudar; problemas sociais e falta de poder econômicos". As causas estão associadas à desestrutura familiar desde fator econômico, grau de instrução, interesses na formação dos filhos e valores éticos e morais, até a falta de perspectivas de futuro. Apesar dessas associações é importante ressaltar que a escola também é responsável pela formação de futuros cidadãos e como tal, com isso, é necessário que esta se torne também protagonista e crie condições, regras e formas para que os alunos possam cumprir dentro do espaço escolar, e, repliquem enquanto seres sociais.

De acordo com as respostas dos pesquisados (professores e alunos), a indisciplina escolar atrapalha o raciocínio dos professores e alunos, e como consequência, reflete no atraso dos conteúdos, e no baixo rendimento escolar dos educandos.

No que diz respeito à aprendizagem dos educandos, esta pode ficar atrelada a indisciplina em sala de aula. O barulho, as conversas paralelas e as "brincadeiras" podem influenciar na concentração e atrapalhar a compressão dos conteúdos nas horas das explanações.

Verificou-se também, que na escola pesquisada, a indisciplina escolar está vinculada a fatores internos, tais como: a infraestrutura, a administração, a relação professor-aluno e ao processo de ensino e aos fatores externos como os problemas socioeconômicos, a baixa qualidade de vida e os conflitos de ordem familiar.

\section{Referências}


BANALETTI, S. M. M.; DAMETTO, J. Indisciplina no contexto escolar: causas, consequências e perspectivas de intervenção. REI-Revista de Educação do Ideau, v. 10, n. 22, p. 1-15, 2015.

BEE, H. O ciclo vital. Tradução de Regina Garcez. Porto Alegre: Artes Médicas, 1997.

BENETTE, T. S.; COSTA, L. P. Indisciplina na sala de aula: algumas reflexões. 2008. Disponível em: <http://www.diaadiaeducacao.pr.gov.br/portals/pde/arquivos/2186-8.pdf $>$. Acesso em: 21 jul. 2019. CHARLOT, B. A escola e o trabalho dos alunos. Sísifo. Revista de Ciências da Educação, v. 10, p. 8996, 2009.

COSTA, M.; KOSLINSKI, M. C. Entre o mérito e a sorte: escola, presente e futuro na visão de estudantes do ensino fundamental do Rio de Janeiro. Revista Brasileira de Educação, v. 11, n. 31, p. 133-154, 2006.

DOS SANTOS, E. R.; ROSSO, A. J. A indisciplina escolar nas representações sociais de professores paranaenses. Psicologia da Educação. Programa de Estudos Pós-Graduados em Educação:

Psicologia da Educação, n. 34, p. 127-157, 2012.

ESTÉVEZ, E.; MUSITU, G.; HERRERO, J. The influence of violent behavior and victimization at school on psychological distress: the role of parents and teachers. Family Therapy, San Diego, v. 32, n. 3, p. 143-156, 2005.

FERNANDES, L. M. et al. Preditores do desempenho escolar ao final do ensino fundamental: histórico de reprovação, habilidades sociais e apoio social. Temas em Psicologia, v. 26, n. 1, p. 215-228, 2018. FERREIRA, A. C. Representações sociais dos alunos do $9^{\circ}$ ano com indícios de minorias ativas em relação à indisciplina escolar. 2019. 248 f. Tese (Doutorado em Educação) - Universidade Estadual de Ponta Grossa, Ponta Grossa, 2019.

GARCIA, R. L. (Org.). Método, Métodos, Contra método. São Paulo: Cortez, 2003.

INEP. Instituto Nacional de Estudos e Pesquisas Educacionais Anísio Teixeira. Indicadores educacionais - Educação Básica - Taxas de rendimento escolar nos ensinos fundamentais e médioBrasil 2012 - 2018. Disponível em: <http://portal.inep.gov.br/artigo/-

/asset_publisher/B4AQV9zFY7Bv/content/inep-divulga-taxas-de-rendimento-escolar-numeros-mostramtendencia-historica-de-melhora/21206 $\geq$ : Acesso em: 27 jul. 2019.

JEROME, E. M.; HAMRE, B. K, PIANTA, R. C. Teacher-child relationships from kindergarten to sixth grade: early childhood predictors of teacher-perceived conflict and closeness. Social Development, New York, n. 18, v. 4, p. 915-945, nov., 2009.

LA TAILLE, Y. A indisciplina e o sentimento de vergonha. Indisciplina na escola: alternativas teóricas e práticas. São Paulo: Summus, p. 9-23, 1996.

MARTINS, L. V.; DE OLIVEIRA, A. T.; NICOT, Y. E. Indisciplina escolar na percepção de docentes e discentes no ensino fundamental. Revista de Estudos e Pesquisas sobre Ensino Tecnológico

(EDUCITEC), v. 2, n. 04, 2016.

MITCHELL, M. M.; BRADSHAW, C. P.; LEAF, P. J. Student and Teacher Perceptions of School Climate: A Multilevel Exploration of Patterns of Discrepancy. Journal of School Health, Chicago, v. 80, n. 6, p. 271-279, jun., 2009.

MURCIA J. A. M. Goal orientations, motivational climate, discipline and physical self-perception related to the teacher's gender, satisfaction and sport activity of a sample of Spanish adolescent physical education students. International Journal of Applied Sports Sciences, New York, v. 17, n. 2, p. 44-58, dez., 2005. NEGREIROS, F.; DA SILVA, A. M. P. M.; LIMA, M. B. P. Experiências educativas não exitosas: um estudo com discentes avaliando seu próprio processo de reprovação escolar. Revista Educação em Debate, 2017.

NUNES, A. I. B. L.; SILVEIRA, R. N. Aprendizagem: um conceito histórico e complexo: psicologia da aprendizagem: processos, teorias e contextos. Brasília, DF: Liber Livro, 2009.

OLIVEIRA, M. I. Indisciplina escolar: determinações, consequências e ações. Brasília: Liber-LivroEditora, 2005.

PARRAT-DAYAN, S. Trad. Silvia Beatriz Adoue e Augusto Juncal - Como enfrentar a indisciplina na escola. São Paulo: Contexto, 2008. 
PENNA, M. G. O. Relações entre professores e alunos: algumas considerações sobre a indisciplina.

Educação Unisinos, v.14, n. 1, p. 11-16, jan./abr., 2010.

QUEIROGA, A. V. Agressividade e indisciplina infantil: reflexões sobre as causas e a intervenção no contexto escolar. 2016.

SALVADOR, R. M. A. Olhar a escola e os outros: Vivências de alunos de $9^{\circ}$ ano com atitudes de indisciplina. 2003. 202 f. Dissertação (Mestrado de Psicologia Educacional) - Instituto Superior de Psicologia Aplicada, Lisboa, 2003.

SAMPAIO, D. Indisciplina: um signo geracional? Cadernos de organização e gestão curricular. Ed. Instituto de inovação educacional, 1997.

SANT'ANA, A. S. S. A indisciplina na Educação Física escolar. 2012.

SANTOS, I. L. et al. As percepções e os significados para os estagiários de Educação Física em relação à indisciplina na escola. Movimento, Porto Alegre, v. 14, n. 3, p. 117-137, set./dez. 2008.

SAVIANI, D. Educação brasileira: estrutura e sistema. Autores Associados, 2018.

SILVA, C. A. et al. Meninas bem-comportadas, boas alunas; meninos inteligentes, indisciplinados.

Cadernos de Pesquisa, n. 107, p. 207-225, 1999.

SILVA, K. E. B. Indisciplina e violência na escola: Um estudo com alunos brasileiros do $8^{\circ}$ e $\mathbf{1 0}^{\circ}$ anos de escolaridade. 2014. 92 f. Dissertação (Mestrado em Educação) - Universidade de Lisboa, Lisboa, 2014.

SIQUEIRA, M. S. C. Indisciplina escolar: contribuições da família e da gestão escolar. 2017.

Dissertação (Mestrado em Ciências da Educação) - Escola Superior de Educação Almeida Garrett, Lisboa, 2017.

TARDIF, M. Saberes docentes e formação profissional. 16 ed. Petrópolis, RJ: Vozes, 2014.

TOMÁZ, T. C. Não gostar de matemática: que fenômeno é este? Cadernos de Educação, Pelotas, n. 12, p. 187, jan./jul., 1999.

VELEZ, M. F. P. Indisciplina e violência na escola: factores de risco: um estudo com alunos do $8^{\circ}$ e $\mathbf{1 0}^{\circ}$ anos de escolaridade. 2010. 177 f. Dissertação (Mestrado em Educação) - Universidade de Lisboa,

Lisboa, 2010.

YAHAYA, A. et al. Discipline Problems among Secondary School Students in Johor Bahru. Malaysia,

European Journal of Social Sciences [s.1.], v. 11, n. 4, p. 659-675, 2009.

ZABALA, A. A Prática Educativa. Como ensinar. Tradução Ernani F. da F. Rosa. Porto Alegre: ARTMED, 1998.

ZANELLA, L. C. H. (2009). Metodologia de estudo e de pesquisa em administração. Florianópolis: Departamento de Ciências da Administração/UFSC, 129-149.

ZIMMER-GEMBECK, M. J.; LOCKE, E. M. The socialization of adolescent coping behaviors:

Relationships with families and teachers. Journal of Adolescence, London, v. 30, p. 1-16, 2007. 